\title{
Knowledge \\ Management: \\ PHILOSOPHY, PROCESSES, \\ AND PITFALLS
}

\author{
Christine Soo \\ Timothy Devinney \\ David Midgley \\ Anne Deering
}

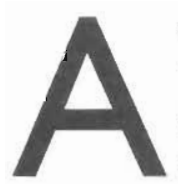

ccording to a leading scholar of management James Brian Quinn, ${ }^{1}$ "The capacity to manage human intellect-and to transform intellectual output into a service or a group of services embodied in a product--is fast becoming the critical executive skill of this era." Contrast that with the assertion by the pointy-haired boss of the Dilbert cartoon that his company's success will be driven by "redesigning processes to enable enterprise integration of knowledge resources and tools." The first is a serious, thoughtful, and eminently reasonable statement of a belief in the transformation of management. The second is a caricature of that belief, subsequently doused by Wally's response, "Is it okay if I do nothing?" Leave it to Scott Adams and his alter egos to gut the sanctity from the latest management fad. Nevertheless, any executive attempting to deal with the reality of knowledge management is faced with a cold hard fact-few know what they are doing when it comes to the management of their firm's knowledge base. Most, like Wally, hope to get away by doing nothing. Provided their knowledge management is not measurable in terms of business outcomes, they can indeed do so. However, they will not be able to get away with it for much longer. While knowledge itself is difficult to measure, it does have a clear impact on business outcomes. More critically, there are good proxies in terms of innovative outputs that can be used to measure whether management is doing a good or poor job of managing their firm's knowledge base.

This research was supported by grants from the Centre for Corporate Change at the Australian Graduate School of Management, the Australian Research Council and AT Kearney. We have benefited greatly from comments and suggestions from participants at seminars at the AGSM, INSEAD, Universität lena, Universität Hamburg. Stockholm School of Economics, the 1999 EGOS Conference at. Warwick University, the 2000 Organization Science Conference and the 2000 Strategic Management Society Conference. 
The need for knowledge management has grown from the recognition that inflexible organizational structures cannot cope when the ground is shifting as rapidly as it does in today's markets. The problem faced by managers is that as customers and markets have changed, the organizational components that need to be managed have become less and less visible. Consider an analogy with physics. Newtonian physics concerned itself with visible phenomena-an object falling in a vacuum or the orbit of a body in frictionless space. Over time physicists found that such simple models could not explain more complex phenomena and, with the concurrent development of better measurement instruments, began delving into the subatomic realm of neutrons and electrons. This was sufficient to keep people busy for a while and led to the development of nuclear power plants, medical instrumentation, and, of course, weapons. However, this reached its limit as more thorny phenomena were studied and more complex instrumentation was developed. Physicists soon found themselves operating in the mystical realm of strings, dark matter, and Einstein's "spooky action at a distance." Few, if any, of these concepts can be articulated in anything but sets of equations and their direct measurement is well nigh impossible. Instead, physicists rely on indirect measurement of specific event outcomes from which it can be inferred that one or other model is correct.

The evolution of physics from the study of observable phenomena with tangible parts to unobservable (but relevant) intangible phenomena with probabilistic parts parallels the demands now facing managers. Management researchers are faced with the added complication that we have not been able to do sophisticated experimentation on organizations. Executives are now confronted with a very serious and currently "unmanageable" imperative-the man. agement of a completely invisible asset - a task made all the more difficult by the tried-and-tested managerial maxim that you cannot manage what you cannot measure. This fact is complicated further by the confusion between data management and knowledge management perpetrated by IT consultants selling knowledge management systems. Data is information. Knowledge, or know-how, has to do with the process of learning, understanding, and applying information. As the eminent philosopher Gilbert Ryle states, "learning how or improving in ability is not like learning that or acquiring information."2 Such a distinction is also reflected in Pfeffer and Sutton's concept of the "knowing-doing gap," which highlights the distinction between "knowing" something and converting what is known into action. ${ }^{3}$ For them it is not enough to know what to do; the challenge is in understanding how to use knowledge to generate results. The importance of the data-knowledge distinction is emphasized in Davenport et al.'s recent work, where they emphasize that although organizations are well equipped to access data, "all too rarely is that data sifted into the sort of knowledge that can inform business decisions and create positive results."

According to Teece, the competitive advantage of a firm lies in its "ability to create, transfer, assemble, integrate, and exploit knowledge assets." ${ }^{5}$ This is a feat that is both challenging and mystifying for managers, as illustrated by 
Ruggles's survey uncovering that managers face difficulties not in accessing knowledge, but in utilizing knowledge in decision making and in embodying knowledge in products/services and processes. ${ }^{6}$ True knowledge, by definition, is non-codified. As soon as it becomes codified and transmittable it ceases to be knowledge and becomes data. It can only become new knowledge when combined in some unique way leading to an actionable outcome. It is this fundamental and embedded characteristic of knowledge that makes its management so frustratingly difficult.

The trouble that managers face in developing and integrating knowledge management practices is that an effective knowledge management system is in itself a complex combination of a series of organizational subsystems which are themselves complex (and only one of which has a strong information technology dimension). A firm's knowledge management system embodies four main. components:

- a database subsystem that allows managers and employees to share the right information in a timely and efficient fashion;

- an organizational language subsystem that allows individuals to understand the meaning of things (this can include understanding information by decoding what they receive from the database, codifying their own knowledge into readily usable data for other users and the systemic language that allows people in an organization to recognize deeper meaning behind verbal and physical communication);

- a networking subsystem that allows individuals to retrieve and acquire information and knowledge from sources both internal and external to the firm (networking subsystems operate on both formal and informal levels); and

- the transfer subsystem whereby systemic knowledge is either directly transferred between individuals or new knowledge is created by the unique combination of information with the individual's experience base (in many ways, this is the most critical subsystem).

If managed in a way that facilitates knowledge development, sharing, and utilization, the ultimate outcome of this combination of subsystems is greater innovative output, either in terms of new products or services or better operational performance.

Our research examines firms' knowledge systems and the impact that they have on the ability of the organization to enhance innovation and financial performance from these underlying subsystems. In its general form, our research surveys the knowledge management processes of 317 firms across a wide range of consumer, industrial, service, and manufacturing sectors using a self-completion questionnaire (the survey research). This work allows us to paint a generic picture of the relationship between networking, knowledge creation, innovation, and financial and market performance. In its specific form, our research investigated the knowledge management systems of six firms from the following 
FIGURE I. The Process of Knowledge Creation and Innovation

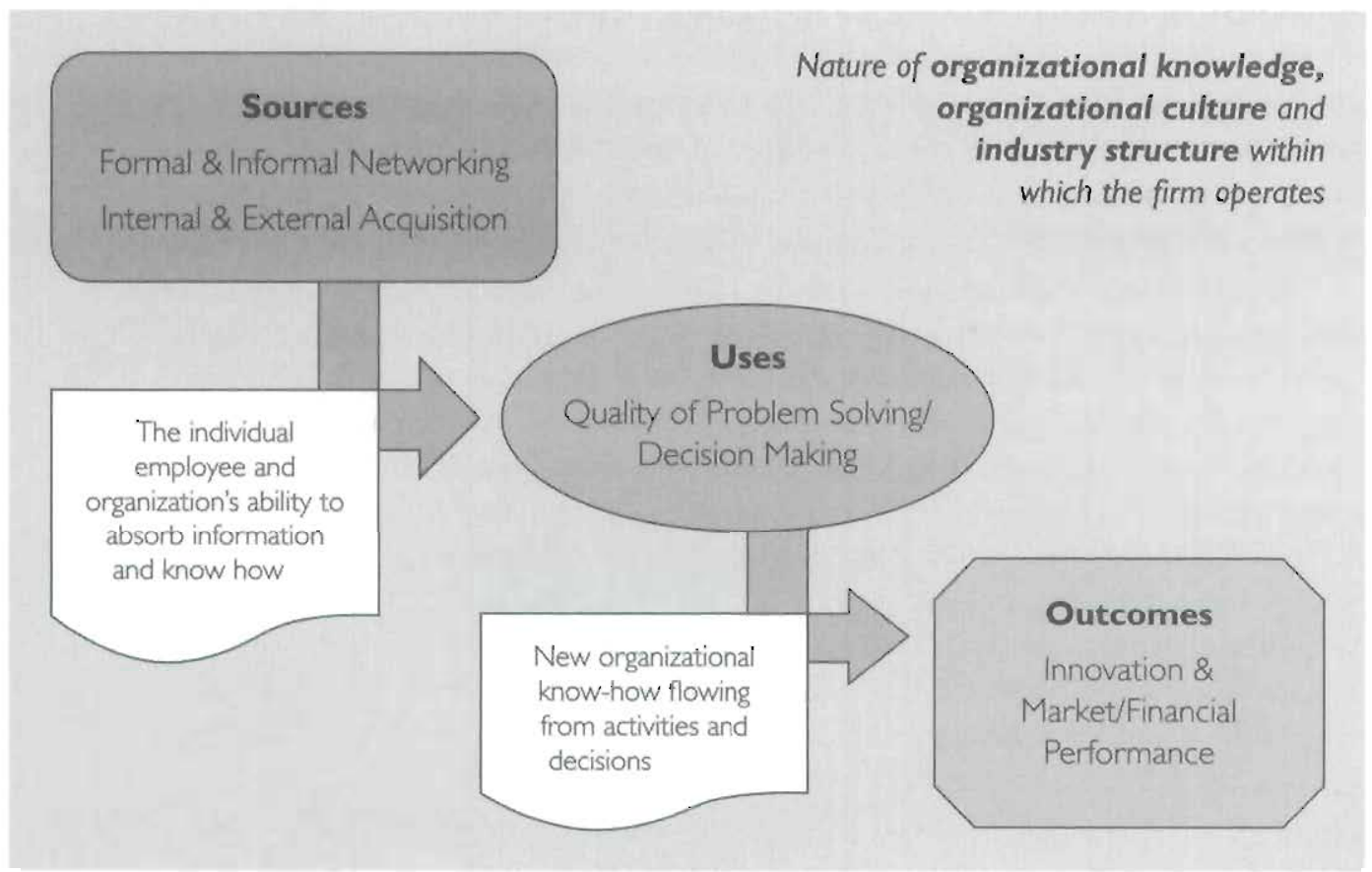

sectors: advertising, business services, executive search, legal services, engineering design, and automobile industries. This was done using a combination of internal surveys and structured interviews (the case research). In both forms, the questionnaires and interviews covered a range of concepts that were central to organizational knowledge management, such as formal and informal networking, absorptive capacity, ${ }^{7}$ quality of problem solving, ${ }^{8}$ and innovation. ${ }^{9}$

Our relatively simple approach provides a clear framework for thinking about knowledge in the context of firm performance. Firms need not necessarily measure knowledge directly to manage it. They can measure knowledge indirectly by measuring certain firm processes (i.e., problem solving and decision making) or outcomes (i.e., innovative outputs) that serve as proxies for knowledge creation.

\section{The General Process of Knowledge Creation and Innovation}

A simple way of thinking about the knowledge-creation process is with a sources-uses-outcomes approach, as exhibited in Figure 1. This approach looks at knowledge creation in three ways. First, there must be sources of information and know-how on which an individual's knowledge base is built. These sources arise from the internal and external network opportunities open to the individ- 
ual attempting to generate and utilize a knowledge base. Operationally, it is measured by the level of information and knowledge that is acquired from an individual's formal and informal networking activities. Second, the organization and individual must have absorptive capacities for internalizing and integrating the information and know-how being extracted from the "network" of contacts and sources. According to Cohen and Levinthal, absorptive capacity is the ability to recognize, absorb, and assimilate new external information. ${ }^{10}$ We adapt the authors' conceptual definitions to derive the following measures: active information and knowledge sourcing, recording and sharing, and knowledge accumulation behaviors (such as participating in conferences, updating skills through training and self-learning, and keeping abreast of the latest technology). In addition to individual-level measures, organizational-level measures are also obtained by investigating the extent to which the firm has policies and procedures that encourage and develop individuals' absorptive capacity. Third, because knowledge is "actionable," it must be created through application. Hence, the catalyst of the knowledge-creation process is the organizational problem-solving context in which we investigate whether the acquired information and know-how influences the quality of the decision-making process. Specifically, we look at whether information and knowledge is utilized in decision making to generate higher levels of comprehensiveness (more thorough analysis of options), creativity (application of novel solutions), consensus (shared commitment to implement chosen options), and new knowledge (new ideas, insights, better problem-solving processes, and new ways of thinking).

From this process, the organization puts itself in a position to generate knowledge-based outcomes; i.e., innovation. We define innovation as a mixture of process and product outputs that include new or modified products and services, patents, new marketing techniques, new managerial tools and administrative processes, licenses, and wider "thought leadership" (represented by things like presentations at conferences and publications). It is these outputs-and not the simple fact that know-how is created-that generate better financial and sales performance. Performance is measured as three-year market share, profits, profit growth, and sales growth (all relative to competitors).

Another characteristic of this approach is its recognition of the environmental milieu in which knowledge creation is taking place. There are two contexts that are important. The first is the simple market/industry context. This is most critical in determining basic structural factors that might affect the pool of available knowledge and innovation as well as the networking limitations. The context provides benchmarks for actual and potential innovative and market/financial performance. The second context is the information and know-how context. Certain business environments will have different information and knowledge structures in terms of the codifiability, teachability, observability, complexity, and cross-functionality of know-how and information. ${ }^{11}$ For example, a legal firm tends to operate in a world with observable, teachable, and function-specific precedents that are driven by the nature of the legal system. 
FIGURE 2. Performance, Knowledge Creation, Absorption, and Networking

\section{Sources}

A. The greater is formal and informal networking, the greater is information and knowledge acquisition.

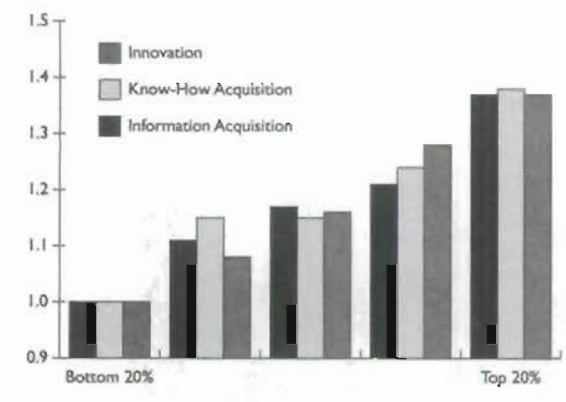

Formal Networking

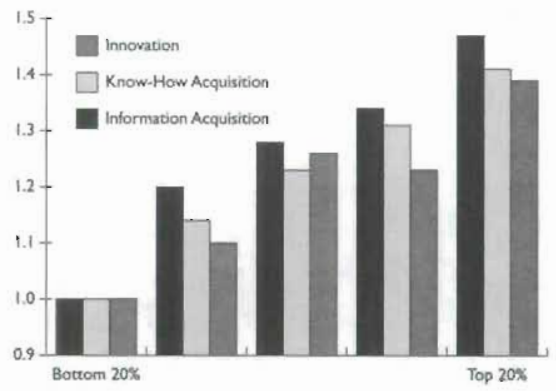

Informal Networking
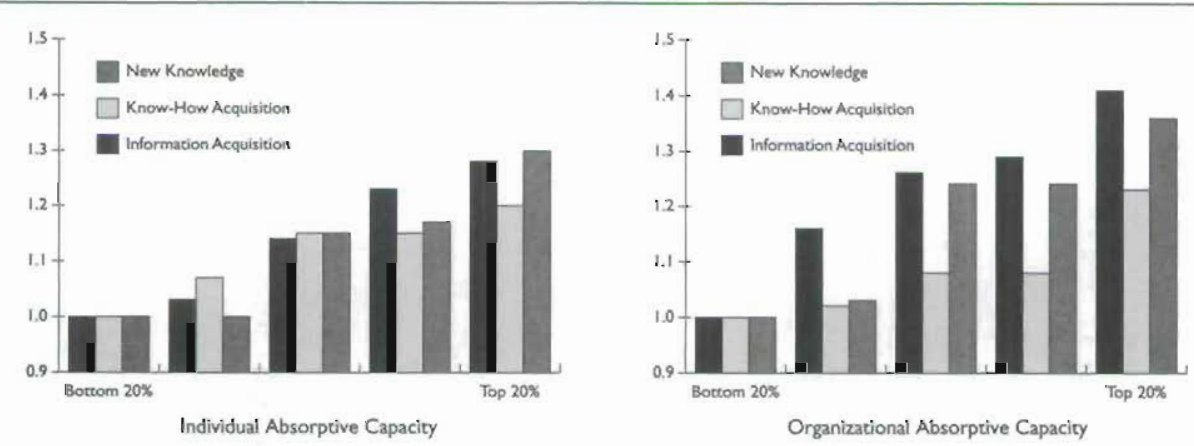

B. The greater individual and organizational ability to absorb information and knowhow, the more new information and know-how is acquired and the better is the basis for decision making.

This might be contrasted with a different world in which, say, an advertising agency operates, where knowledge is more tacit and experiential.

Figure 2 shows a stage-by-stage examination of the 317 firms that responded to a mail survey. ${ }^{12}$ The five sets of columns represent ranked groupings for each fifth of the sample based on the measure shown on the horizontal axis, with the set of columns for the top fifth of the sample displayed on the right hand side of each chart. The height of each column represents an index for the dependent measure whose name is given in the legend. The index sets 
FIGURE 2. Performance, Knowledge Creation, Absorption, and Networking (continued)

\section{Outcomes}

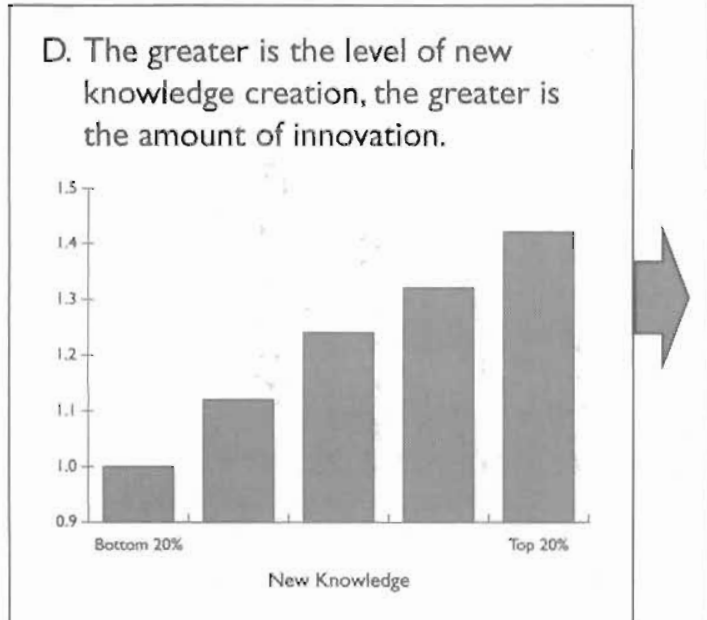

$E$. The greater the amount of innovation, the greater the market and financial performance.
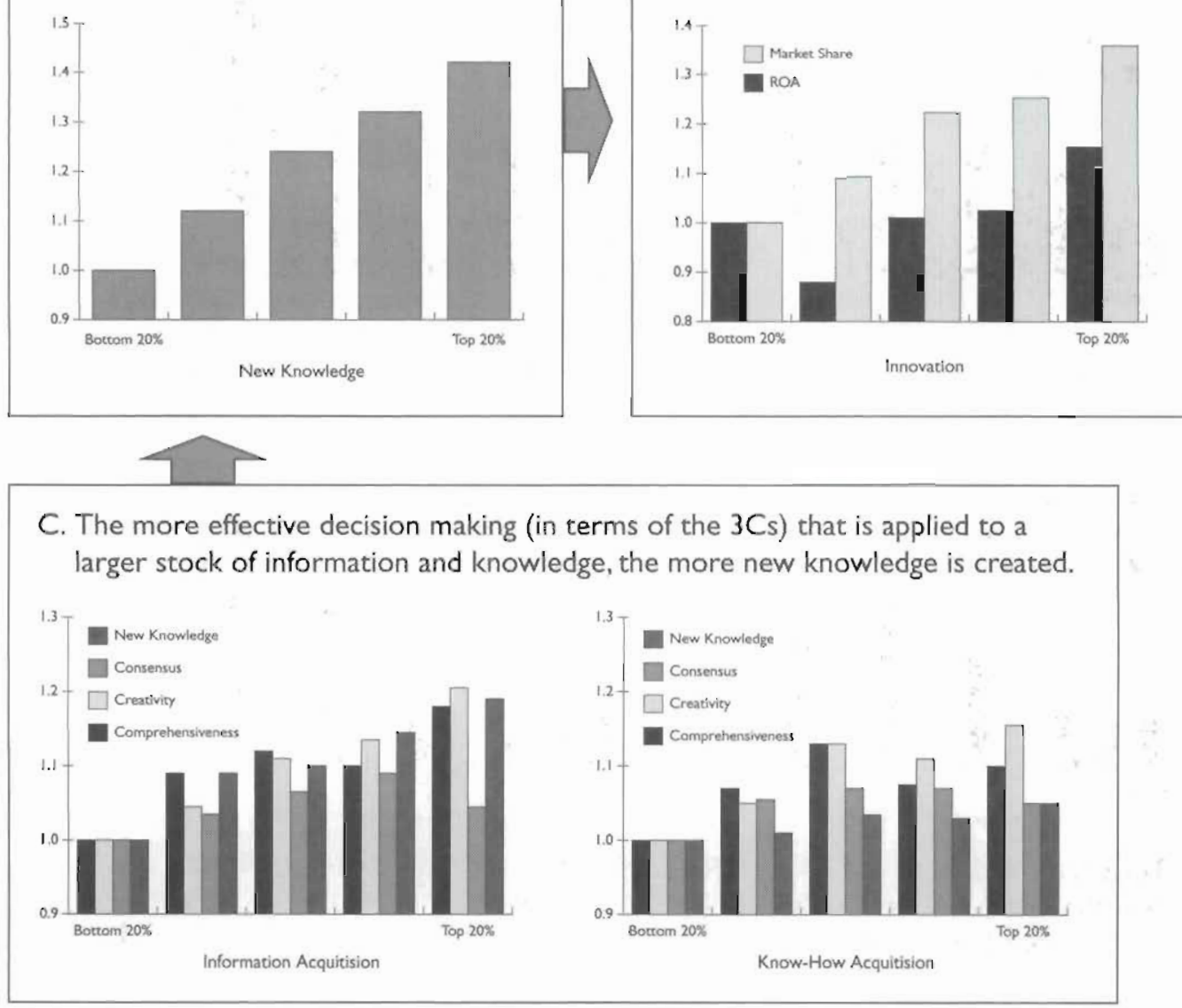

\section{Uses}

\footnotetext{
Note: The constructs are as follows: Formal Networking; Informal Networking; Information Acquisition-Stock of information acquired from networking; Know-tiow Acquisition-Stock of know-how sources acquired from networking: Individuat Absorpove Copacity (AC): Organizational Absorptive Capacity (AC): Comprehensiveness - Comprehensiveness of decision making; Consensus - Consensus used in decision making: Creativity - Creativity brought to bear in the decision making process; New Knowledge created from decision making; Innovotion-Index of innovative outputs. Two performance measures are presented — ROA (Return on Assets Relative to Competitors) and Market Shore. For example, in reading the last box it indicates that the bottom one-fifth of innovators has a market share $36 \%$ below that of the top one-fifth.
} 
the measure for the lowest fifth of the sample to 1.0 and scales the others in proportion. For example, in. "Sources" the top fifth of the sample based on our measures of "Formal Networking" clearly outperforms the bottom fifth on the three measures of "Information Acquisition," "Know-How Acquisition," and "Innovation." The indices for these three measures (column heights) are approximately 1.35-that is, 35\% greater than for the bottom fifth of the sample. The point of the exercise is to show that-as one progresses through the process of sourcing to use to outcomes-firms doing the best sourcing with the best absorption with the best decision-making processes are the most innovative and the top financial and market performers. We have eschewed statistical measures for simplicity. However, the picture presented is confirmed by more sophisticated analysis. ${ }^{13}$

Block A of the figure shows that the greater the level of formal and informal networking, the greater the level of information and know-how stock available to the firm. ${ }^{14}$ Our definition of formal networking includes the use of formal data systems and hence accounts for the database subsystem discussed earlier. All told, the firms with the least formal and informal networking have know-how and information sources that are 30-40\% below the best one-fifth of firms. Information and know-how stock represent the sources of data, information and knowledge resident in other sources (other people, consultants, advertising agencies, research centers, and so on). Block B shows that the firm's and individual's ability to absorb knowledge and information is also critical to generating a solid base for new knowledge creation. The top fifth of firms and individuals in terms of absorptive capacity significantly outperform all others in terms of information and know-how generated from external and internal sources and also in terms on new knowledge created. Block $\mathrm{C}$ examines the relationship between the stock of available information and knowledge and the decisionmaking performance of firms and their ability to create new knowledge. Firms with the largest available stocks of information and knowledge are more likely to create new knowledge predominantly through the level of comprehensiveness and creativity of their decision-making. What is interesting is that information stocks are more important to new knowledge creation than knowledge stocks. This follows from the fact that new knowledge is something available to the firm through its actions, while knowledge embodied in other external and internal sources may be less readily applied to decision-making. Block D shows that firms that create the most new knowledge are the most innovative, while Block E takes this to the final financial and market conclusion: the most innovative have the best market share and the best profit performance relative to competitors (although the market share results are much clearer).

This set of results provides us with a deeper understanding of the role of information and knowledge in influencing specific organizational processes and outcomes. It also provides us with an interesting managerial conclusion. Authors such as Ruggles ${ }^{15}$ have shown that a major stated issue for those attempting to manage knowledge is the measurement of knowledge and 
determining which knowledge is useful. According to our work, this may be an unnecessary - or at least not fatal-concern for some firms. Because we know the antecedents (networking and absorptive capacity), germinators (decision making quality), and outcomes (innovation) of knowledge creation, much of the problem of knowledge systems can be resolved by focusing on creating the right environment for these components to operate effectively. This, of course, does not mean that firms shouldn't worry about database content and measuring information and knowledge, but that it: is just one component of the knowledge management system.

In fact, recent work by Gold et al. indicated that knowledge management should be seen from an organizational capabilities perspective. ${ }^{16}$ That is, the ability to apply knowledge in problem solving (i.e., process capability) is just as important as the ability to store knowledge (i.e., infrastructure capability). Indeed, this is one of the compelling lessons of the Buckman Laboratories example. ${ }^{17}$ Buckman did not focus on content but rather on making sure that those who needed access to sources of know-how got it and were capable of understanding what to do with it once they had their hands on it.

\section{Knowledge Traps: \\ Lessons from the Management of Knowledge}

Subsequent to the work described above, we also examined both quantitatively (through internal surveys) and qualitatively (through interviews) the knowledge management practices of six firms. These firms also represent a cross-section of industries. Two of the firms were industrial in orientation with large labor forces - one in automobile engine design and manufacturing and the other in railway engineering design. Three were professional business service organizations that were large in their respective markets and also respected for their financial and service quality performance-one each in legal services, business services, and executive search. The last firm was a small advertising partnership. In total, these firms generated another 357 survey responses and 150 interviews.

We observed a set of "knowledge traps" to which even the best firms seemed to fall victim. These pitfalls are "managerial." in that they relate directly to decisions (or non-decisions) made by managers who caught the knowledge management bug but failed to recognize that knowledge management is a philosophy about business operations, not a simple process that can be bolted onto business models, as in the case of quality function deployment, business process reengineering, or total quality management. Also, the intangibility of knowledge means that the things that made QFD, BPR, and TQM popular-i.e., their measurement capabilities-are absent. Without good metrics, managers of knowledge-based. firms traded measurement for gut instinct, and in the process they allowed themselves to make some simple but critical errors. Following are eight lessons to be learned from these knowledge traps. 


\section{Lesson 1: Formal databases must be treated as strategic tools rather than mere storage facilities.}

An organization's database subsystem can be an important repository of the wealth of information that resides within the firm, provided that it is structured and designed for that purpose. We came across several examples where firms had invested in formal systems that failed to develop into a strategic tool. for enhanced problem solving simply because: they were cumbersome to use; their content was not useful or relevant enough; and insufficient effort was put into transferring the intellectual capital from the people onto the system. More formally, the database subsystem failed to merge effectively with the other knowledge management subsystems - transfer, language, and network.

Both the business services and legal firms examined had in-house database systems that were perceived to be both too complicated (for inputting as well as retrieving data) and inefficient (in terms of the time taken to retrieve a piece of information). More importantly, the information and knowledge stored were not perceived as being comprehensive or sufficiently relevant. In the business services firm, this was attributed to the fact that the people managing the system did not possess adequate "industry or specialist knowledge" to enable them to understand a particular client's problem nor did they possess the information required to solve it. Finally (and this remains the most difficult aspect of managing formal databases), there must be a concerted effort on part of the organization to ensure that any part of knowledge that is codifiable is indeed codified and captured. One of the business services firm's biggest challenges was capturing the intellectual capital that flowed from client projects. The difficulty was the lack of time and incentives allocated for recording knowledge, as illustrated by one associate's statement: "No one is given time to actually do it. You come off one client and move onto the next one. That [recording] is the part left undone. It just continues to be on your list and just never gets done. It's not looked on as an important thing."

\section{Lesson 2: Managing formal database systems per se does not equate to knowledge management.}

There is a major distinction between the database subsystem and the knowledge management system. Database subsystems are important vehicles for capturing information, but in order for these to be used effectively, they have to be supported by a strong informal networking subsystem. This is because a database subsystem is not a mechanism that develops in isolation. It needs to be subsumed (and developed and augmented) within an organization's networking and transfer subsystems. Firms with more comprehensive and knowledgefriendly informal networking systems are better at generating know-how and the innovation and performance outcomes that follow. These results echo McDermott's argument that information technology cannot deliver knowledge management because human relationships are needed to share knowledge that is neither obvious nor easy to document. ${ }^{18}$ Few managers know how to make the 
informal structures work. It is much easier to spend a million dollars on formal database subsystems that no one really uses, or uses ineffectively, than to invest in the informal networking and transfer subsystems that are essential for what goes into and comes out of these databases.

However, this does not imply that one must nurture informal networking subsystems at the expense of formal systems. Rather, both complement one another and must be developed concurrently. Strong informal linkages supported by comprehensive databases characterize an organizational environment conducive to generating new ideas and innovation. Effective knowledge management involves managing both formal and informal systems and recognizing that the effectiveness of one can benefit the other.

\section{Lesson 3: Informal networking is an important source of knowledge, but over-reliance on it can be detrimental.}

The importance of informal interactions has been argued by many as a crucial element in knowledge exchange, particularly due to the tacit nature of knowledge that makes it difficult for formal codification and transfer. Sociologists such as Granovetter argue that "economic action (like all action) is embedded in ongoing networks of personal relationships rather than carried out by atomized actors." ${ }^{19}$ This is supported by the work of Nahapiet and Ghoshal ${ }^{20}$ and Cohen and Fields ${ }^{21}$ who acknowledge the important role social capital plays in the development of organizational knowledge and innovation. For many organizations, informal channels of communication have been a rich source of information and knowledge that cannot be found in company databases, manuals, or newsletters. A director of the executive search firm in our sample regarded informal networking as a must-have ingredient for his organization: "For this organization to work effectively, you need to network and you need to network across a range of areas within the business. I don't believe there are formal channels that exist in a way that's easy for you to run your business, so you need to have a lot of informal channels of communication."

We also found instances where informal channels have become the de facto knowledge management system when formal channels have proved inadequate. The inefficiency of the formal database subsystem at the business services firm resulted in many consultants adopting a "hunting and gathering" approach to information and knowledge sourcing, relying on personal networks developed through previous projects or social interaction. In another example, our research at the legal firm revealed that the grapevine had become a substitute when formal communications had failed. Noted one manager at that firm: "The formal communication channels are not strong, or limited in some respects. It's probably not an organization which widely shares information about what's going on, but the informal communication channels (i.e., the grapevine) works fairly well."

Despite the prevalence and advantages of informal channels, there is an inherent risk of spontaneity - that is, the risk of these informal interactions 
being too dependent on "chance meetings." This lack of structure within informal channels can result in important information being lost-there is no guarantee that an essential piece of information will be communicated to all relevant parties. We found various instances where information sharing was random and incidental. One attorney articulated how at his firm: "Information is shared anecdotally and sometimes by sheer luck because sometimes you do it by walking around the floor and asking people. It's quite surprising what I have found by sheer accident." This anecdotal sharing may work for smaller firms, but as organizations grow in size, it becomes more and more random and people need to rely on the strength of their personal networks. A principal at the business services firm noted that information sharing was becoming increasingly unreliable as the firm experienced rapid growth, thus making it difficult to track the knowledge base of the firm: "Information sharing within smaller project teams is very good. Then comes the use of personal networks, and beyond that it is quite difficult to find out who knows what and whom I should approach. So there is a certain amount of luck involved."

Over-reliance on informal networks as the main source of information and knowledge can be detrimental in the long run, especially for larger organizations where knowing "who's who" becomes increasingly difficult. This can be seen as a problem where people are unable to locate a particular source of expertise within the firm. This can be counteracted by having in place an effective formal database system that allows employees to search for a piece of information or knowledge, or at least locate the person who may have that knowledge. Hence, to reinforce the previous lesson, formal and informal systems of exchange must co-exist to support each other. Another guard against the randomness of informal networks (and hence the sharing of information and knowledge) is simply to make them more structured.

\section{Lesson 4." To ensure that informal networking is less susceptible to randomness, it should be made more structured.}

Because knowledge resides within the individual (or groups of individuals), the challenge for managers is to leverage that individual's knowledge across the organization. This is particularly important when knowledge (or best practices) developed in one area of the organization can be applied and utilized in other parts of the organization. All too often organizations fail to account for factors that inhibiting knowledge transfer and diffusion within the firm.

In our research, we have come across many instances where solutions or best practices developed in one part of the firm do not travel to other parts where they can be re-applied-a reflection of what is sometimes called "internal stickiness." Internal stickiness can be thought of as "the difficulty of transferring knowledge within the organization" attributable to organizational structures that promote a "silo" mentality, ${ }^{22}$ a culture that values personal expertise, and the lack of appropriate rewards and incentives for sharing of understanding. ${ }^{23}$ Because the complexity of a problem-solving situation is usually embedded 
within group dynamics, it is common for a solution or a new piece of knowledge to stay within the group whose members most easily understand it. Also, the fast-paced working environment of many firms preclude any real opportunities for people to interact beyond their immediate work group or team, further reducing the chances of cross-divisional sharing. This particular problem can be seen as one of "localized (or divisionalized) problem solving," a phenomenon that is quite prevalent among the firms that we have studied.

One of the main factors contributing to the problem is a lack of structured time for knowledge sharing. As noted, the tacit nature of knowledge means that. it is most effectively shared or transferred through informal interpersonal interactions. However, when there is no structured time scheduled for such purposes, the sharing of knowledge remains ad hoc or accidental. A partner whom we interviewed at the advertising agency commented on how lack of time had worked against the general desire for knowledge sharing in his firm: "There's lots of great little things that we've done for clients that we could share with the rest of the agency and we haven't. It comes down to lack of time more than anything, rather than the lack of will to do it." A manager at the automobile firm also alluded to the problem of lack of structured time in bemoaning how "People find it difficult to get together and share. Lack of time is often the excuse, but what is contributing to our lack of time is our lack of structure to time."

For companies facing a fast-paced working environment, this lack of structured time may be even more detrimental as new knowledge becomes lost and mistakes (when not dealt with in a timely fashion) are perpetuated. At the advertising firm, employees were not learning from mistakes simply because they had not instituted regular structured meetings to serve that purpose. The core output of an advertising agency is highly dependent on different areas of expertise-e.g., client management, creative design, and production. This multidisciplinary work environment, coupled with a fast-paced work culture, creates a need for more regular and structured "de-briefing" sessions where people have the opportunity to discuss mistakes made and lessons learned from their projects. As a director at the agency described the current situation: "We sit down every couple of months and look at mistakes instead of learning instantaneously from something that went wrong. I think it's important to share these things as you're going along, rather than analyze three months down the line when it's too late." An engineer at the railway organization expressed similar concerns that his firm needed to encourage learning by "having internal dedicated time for formal sharing of knowledge."

Opportunities for knowledge sharing are critical to developing a transfer subsystem and come in many forms-e.g., weekly presentations, breakfast meetings, project de-briefs, or mentoring schemes. Merely having these forums on the books is not enough; what is more important is an explicit intention to build in the time for employees to learn from each other. A director at the advertising firm emphasized the significance of regular informal interactions that are 
TABLE I. Assessment of Organizational Incentives for Knowledge Absorption

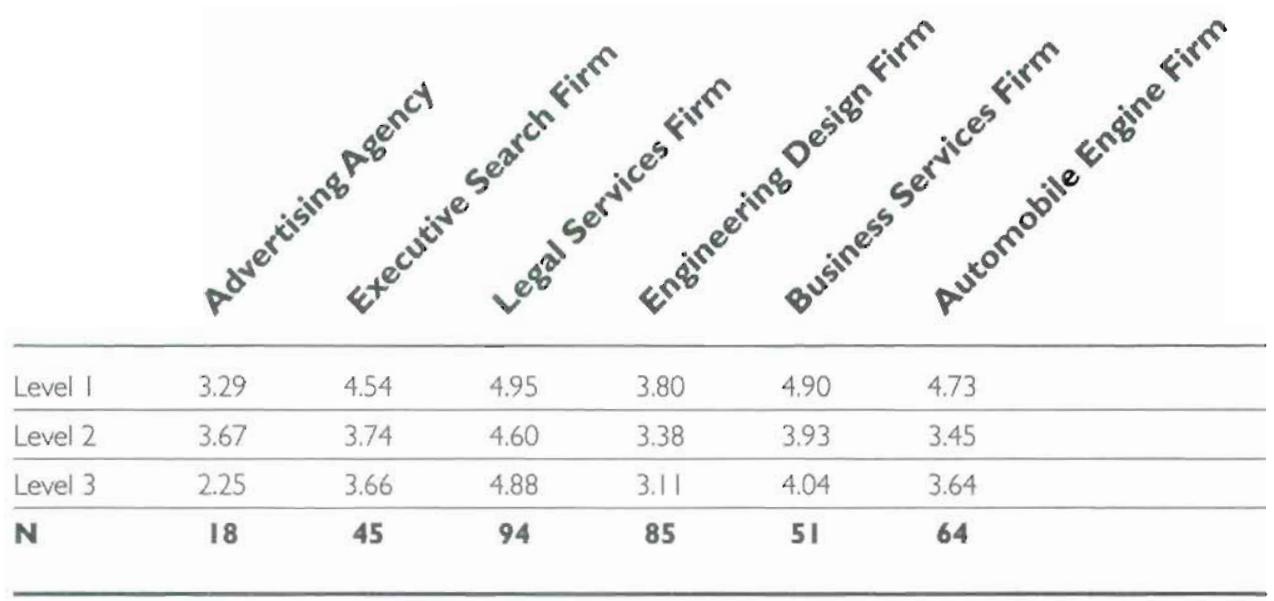

designed for employees to learn from each other: "I think it would be good if all the creative people (even if just once a week) all got together and discussed the projects they're working on and got each other's opinions and feedback-just a bit of creative interaction."

These examples reflect both the importance and difficulty of implementing structured knowledge sharing. Most organizations exist in a world of tight schedules, multiple projects, and quick turnaround time. In this environment, meeting client deadlines is given priority ahead of occasions for general learning and knowledge sharing. However, organizations often suffer the consequences of this oversight when they fail to capture and share the intellectual capital that is produced from the projects they undertake. This is especially true for service organizations where only a small proportion of their intangible know-how can. be codified and the more tacit components will be lost if not shared via regular, structured interpersonal interactions.

\section{Lesson 5: Senior management may not know the true state of their firm's knowledge systems.}

There is a distinct difference between the perceptions of senior managers and their subordinates of the efficacy of their knowledge management systems. With regard to formal database subsystems, senior managers invariably look on the IT systems positively but with a mea culpa related to their own failure to use them effectively. Junior managers are cynical about the systems but much more positive about their own abilities to use them to their own benefit. With regard to the less-tangible management development activities within the firms-i.e., knowledge-sharing practices, training schemes, and keeping abreast of the latest products or industry trends-we found an interesting discrepancy between the perceptions of senior managers and the more junior staff. Senior managers have 
TABLE 2. Organizational Incentives for Knowledge Absorption Relative to Individual Activities

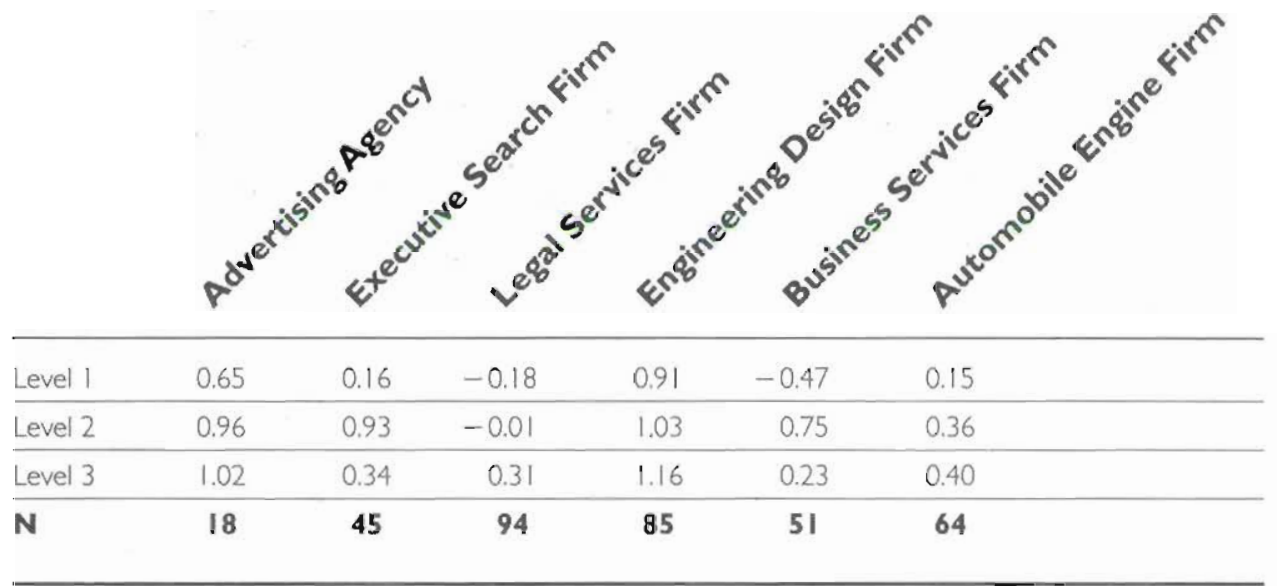

a higher perception of the effectiveness of organizational policies, as compared to lower-level executives. Table 1 shows the ratings (on a scale from 1 to 7 ) given to the organizational incentives for various information and knowledge development activities. ${ }^{24}$ For each case study firm, the survey respondents are divided into three levels-Level 1 being directors and senior managers, Level 2 consisting of middle management, and Level 3 being predominantly team leaders or officers. Results show that for all measures of organizational incentives, Level 1 managers gave the highest ratings in all cases (with the exception of the advertising firm where Level. 2 managers rated higher). The main insight to be gained from this result is that the attitudes of senior managers are not necessarily the only or best measures of the success of any knowledge management system.

\section{Lesson 6: You can't teach old dogs new tricks.}

A finding related to lesson 5 is that firms fail to recognize that certain individuals are either innately unable to absorb new knowledge or their personal and organizational incentives make them unlikely to ever want to do so. For example, one firm had invested enormous amounts of money in knowledge and training activities, to little avail. The problem was not the effectiveness of these activities - they were good-but the fact that the average worker in the company had been working there since their late teens and had been on the shop floor for 25 years. For a worker in this company, risk taking was discouraged since the level of engineering precision required for success was uncompromisingly high and there was no personal reward for absorbing any new knowledge other than that directly related to these precise requirements. Table 2 repeats the breakdown seen in Table $\mathrm{I}$ with an additional twist by 
representing the difference between the individual's evaluation of the organizational incentives relative to their own efforts and ability. ${ }^{25}$ The fact that the individuals consider their abilities higher, on average, than the organizational incentives is not surprising. What is more surprising is the fact that the highest managerial level is always the lowest on this measure. In the case of all six firms, Level 2 and Level 3 managers rate their abilities much higher relative to organizational incentives than do Level 1 executives. Given that Table 1 showed these managers rate the organizational incentives highest, we have an interesting problem: senior managers are more likely to believe in the value of organization incentives (which they no doubt instituted) while being far less likely to engage in the activities those incentives are meant to encourage. Middle and junior managers believe in the incentives less, but still engage in active knowledgeabsorbing activities (most likely because it is good for their own career development).

\section{Lesson 7: Unless carefully managed, knowledge is a dark power.}

A major problem for all the firms in our sample is how to generate knowledge that can be capitalized on for the firm. Knowledge does not reside in databases and (legal issues of intellectual capital ownership aside) information is at best a comparative advantage for the organization. Knowledge resides in individuals and there is always the problem of who gets the rents from its utilization-a fact reinforced in more organizations with "siloed" organizational structures that promote a culture of personal expertise and direct billing responsibility. In two of the firms studied, we came across instances where knowledge absorption at the individual level (predominantly through informal personal networks) did not contribute to the pool of knowledge available to the organization as a whole and most of the rents went directly to the individual (sometimes even to the detriment of the firm). In the executive search firm, a turnover rate of nearly $40 \%$ per year in consultants created a serious problem in maintaining consistency of relationships with corporate clients, and it reduced the likelihood that employees would invest in firm-specific know-how. One attorney in the law firm saw this quite clearly: "There is also a culture that is a real hindrance to the sharing of knowledge. I think it comes from some people believing that knowledge is power and because people's remuneration is very typically based on billings, people will hang on to clients and knowledge and not want to share it."

The solution to this problem is daunting but not insurmountable. It is intertwined with the nature of the transfer and networking subsystems and with where the employee's loyalty lies. In the case of the advertising agency, business services company, law firm, and executive search firm, the employees are quite customer-focused, rely very heavily on the customer for information and knowhow, and generally put loyalty to the customer over loyalty to the firm. The fact that they do so is a conscious policy of their organizations, and effective sharing needs to be considered in light of this. As long as knowledge sharing can be 
shown to improve a specific executive's relationship with his or her clients, it is more likely to occur and will indeed be sought out. However, in cases where information or knowledge sharing is less tied up with the day-to-day business objectives, formal transfer and networking are less valuable (and more difficult to institute) because the holder of the knowledge needs to understand and trust the receiver of the knowledge. Bob Buckman calls this "virtual trust." 26 In the case of the engineering and rail services companies, this is less relevant, as knowledge sharing is not as firmly embedded in their work processes and hence formal administrative intervention is more likely to be effective.

\section{Lesson 8: Creativity in problem solving is the main driver of new knowledge creation and innovation, but it needs to be supported by appropriate mechanisms.}

Creativity is the main driver in new knowledge creation and the generation of innovative outputs. Those firms with the biggest bang from their ability to source and absorb knowledge and information are those that apply it creatively. Because it is in an industry that demands originality, the advertising firm in our sample is well equipped with creative individuals. However, the biggest challenge facing the firm is a lack supporting mechanisms that allow the firm to fully capitalize on its creative potential (i.e., structured time for developing and sharing new ideas). As a manager at the firm explains, "There is a lot of ability to be innovative, but it boils down to a lack of time. Most people here would be more than happy if they had more time to come up with new ideas and be more proactive with the clients." The executive search firm faces a similar problem whereby its incentive structures have prevented the full realization of its creative talents. According to a director of the firm, "One thing that we have is people who are capable. It's not a question of capability; it's a question of what is rewarded. If everything is based upon outcomes [financial outcomes and transactions], then it's in everyone's interests not to worry about quality and just. focus on outcomes. We've never been comfortable taking people out of the revenue stream and saying forget about your billings, we just want you to develop this new product." When creativity is allowed to flourish, it leads to new knowledge and greater innovation. However, it also needs supporting mechanisms to channel that creativity into more effective decision-making processes.

\section{Conclusion: Knowledge Management: Can Be Measured Through Innovative Outputs}

A lot of the initial managerial thinking on knowledge management arose from the IT literature ${ }^{27}$ and the sharing and use of data. On the other side, notions of intangible knowledge stocks ${ }^{28}$ and their role in fostering innovation ${ }^{29}$ have emphasized the role of transfer, understanding, and learning. Our research shows that knowledge management is best understood and managed from the perspective of innovation and intangible asset management rather than IT 
management. Indeed, the impact of knowledge management systems on performance relates primarily to the organization's ability to innovate-either through improved processes or improved products and services. Rather than being a new field of management with its own special laws, knowledge management sits well within our understanding of what drives change and motivates innovation.

\section{CASE STUDY: Managing Know-How ADCO}

"ADCO" [pseudonym], a medium-sized media design-and-execution company, had achieved phenomenal growth since its inception in 1990. With this growth came some unexpected challenges, not the least of which was the fact that growth created pressures to design systems to replace the hands-on management style typical of small start-ups. For Paul Royale, one of the founding partners, the main problems ADCO was grappling with were communication. lack of respect, lack of competences, and the lack of a post-project review process. His eyes were opened to the idea of knowledge being regarded as a currency that was worth something to other people. The problem was to encourage people to share the knowledge. This was the charge given to him by the seven partner/owners.

Knowledge sharing was particularly important to a company such as ADCO that operated in a deadline-driven business where you simply have to do "what the clients want ... when they want it." Whereas client management was one of ADCO's key strengths, managing internal relationships took something of a back seat. Working well with clients did not necessarily extend to working well with colleagues. As one director noted, "We all work well with clients, but I think internally we are absolutely appalling at sharing how we work... ways of working smarter." As ADCO grew, the informal networking between the partners that made it operate smoothly was put under stress.

Paul Royale found that five levels of knowledge were critical to the agency's success. The first was technical expertise - how to make effective videos and other promotional material. The second was project management--the understanding of what it takes to put a major project together for a client. The third was understanding client needs and delivering marketing value for clients (which has historically been the competence that sets ADCO apart from most of its competitors). The fourth was the ability to seek out and absorb "what's new," fresh and trendy in the industry. The fifth, and perhaps the least important, was the storage and retrieval of ongoing internal knowledge development.

Recognizing that a firm the size of ADCO (with 51 full-time employees and an equal number of temporary workers) could not afford complex database systems, Paul Royale focused his efforts on developing an informal networking and transfer systems that substituted for expensive IT and fit better with the company's "creative" focus. The result was three initiatives.

- The After-Action Review process was aimed at facilitating more constructive feedback and eliminating mistakes after the completion of each project. The business directors decided 
to try it for a period of 3 months to see if it worked. As one director emphasized the importance of such reviews, especially their timing: "We used to sit down every couple of months and look at mistakes instead of learning instantaneously from something that went wrong. I think it's important to share these things as you're going along, rather than analyzing them three months down the line when it's too late."

- Show-and-Tell allows people to do a short presentation of work that has been done for certain clients to the rest of the agency. In addition, senior managers give 20- to 30-minute talks on areas they felt would benefit the agency as a whole. The topics discussed have been fairly broad, such as life skills or relationship management skills.

- Informal Brainstorming Sessions have been instituted at the initiation of large client projects. Part of the impetus behind these meetings was the failure of communication between the different client groups. This lack of information sharing was highlighted when the one team wanted to use "heat reveal" promotional material. Because nobody on the team had any experience with the technology, they went through a long learning process. In fact, it took several weeks of painful and expensive research. In the end, the team found a company that specialized in developing heat-reveal promotional material. When the company was contacted, the team found out that another group at ADCO had worked with this same company several months before on a promotion for another client.

These informal structures were critical to ADCO's success. They systematized meetings and interactions, avoided the failure to reuse relevant information, and highlighted the sources of knowledge inside the firm. Although many in the company bemoaned the fact that most of the larger mainstream agencies had research departments or resource libraries that kept them up to date, it was clear that ADCO could not afford to operate such a system and that informal development was more efficient. However, this did not mean that they ignored more formal database systems. Plans were on the books to develop a database of detailed information on each employee as a way of encouraging people to get to know each other more as well as becoming a source of business-related information. Plans were also in place to update ADCO's current database - a centralized repository of client names, contact numbers, and other superficial information that is updated by the client service people responsible for their respective clients. However, given the "creative" and "informal" nature of ADCO's culture it was felt that such systems could not replace the more humanistic approach to knowledge management.

This creates a convenient solution for managers trying to deal with the intangibility of knowledge. Most critically, managers can measure the change in innovative outputs that flow from knowledge management strategies and practices. Although not perfect, such simple thinking has been shown to dramatically increase the respect for knowledge management, increase the innovative performance of firms, and ultimately filter through to the bottom line.

Knowledge management systems operate very much on a contingency. "horses for courses" platform. The level of emphasis on the various subsystems differs quite dramatically from firm to firm, even though the basic problem is the 
same: how to generate and capitalize on knowledge. This is emphasized in the case of the advertising agency. "ADCO" (see sidebar). What this case illustrates is the difficulty faced by an in-between firm-an organization too large for purely informal systems to operate but too small to afford complex and formal corporate systems. The firm was successful in that it understood what it needed to know and tried to develop systems that achieved that.

\section{Notes}

1. J.B. Quinn, Intelligent Enterprise: A Knowledge and Service Based Paradigm for Industry (New York, NY: Free Press, 1992).

2. G. Ryle, "Knowing How and Knowing That," Proceedings of the Aristotelian Society, $46(1945-1946): 1-16$.

3. J. Pfeffer and R.I. Sutton, "Knowing 'Whar.' To Do is Not Enough: Turning Knowledge into Action," California Management Review, 42/1 (Fall 1999): 83-108.

4. T.H. Davenport, J.G. Harris, D.W. De Long, and A.L. Jacobson, "Data to Knowledge to Results: Building an Analytic Capability," California Management Review, 43/2 (Winter 2001): 117-138, at p. 117.

5. D.J. Teece, "Capturing Value from Knowledge Assets: The New Economy, Markets for Know-How, and Intangible Assets," California Management Review, 40/3 (Spring 1998): 55-79, at p. 75.

6. R. Ruggles, "The State of the Notion: Knowledge Management in Practice," California Management Review, 40/3 (Spring 1998): 80-89.

7. W.M. Cohen and D.A. Levinthal, "Absorptive Capacity: A New Perspective on Learning and Innovation," Administrative Science Quarterly, 35/1 (March 1990): $128-152$.

8. A. Ginsberg, "Minding the Competition: From Mapping to Mastery," Strategic Management Journal, 15 (Winter 1994): 153-174.

9. D. Leonard-Barton, Wellsprings of Knowledge: Building and Sustaining the Sources of Innovation (Boston, MA: Harvard Business School Press, 1995); I. Nonaka and H. Takeuchi, The Knowledge-Creating Company (New York, NY: Oxford University Press, 1995).

10. Cohen and Levinthal, op. cit.

11. U. Zander and B. Kogut, "Knowledge and the Speed of the Transfer and Imitation of Organizational Capabilities: An Empirical Test," Organization Science, 6/l (January/February 1995): 76-92.

12. The initial mail sample included 2,137 firms. These firms represent a cross section of industries categorized as: mining and oil refineries $(6 \%)$, chemicals 8 pharmaceuticals $(11 \%)$, primary metals $(4 \%)$, machinery, equipment, instruments $(21 \%)$, banking and finance ( $14 \%)$, business services $(21 \%)$, health and legal services $(10 \%)$ and engineering and architecture (13\%). The sample also consists of a range of firm sizes (measured by the number of employees): small firms (less than 100 staff) make up $40 \%$ of the sample, medium-sized firms (more than 100 , but less than 700 staff) make up $30 \%$, and the largest firms make up the remaining $30 \%$.

13. Interested readers are referred to C.W. Soo, "The Process of Knowledge Creation in Organizations," unpublished doctoral dissertation, Australian Graduate Schoo! of Management, University of New South Wales, I999; C.W. Soo, D.F. Midgley, and T.M. Devinney, "The Process of Knowledge Creation in Organizations," unpublished working paper, Australian Graduate School of Management, 2001. 
14. The constructs fall into two general categories: entropy indices and reflective measures. Formal and informal networking, information and know-how acquisition, and innovation were measured using entropy indices. The benefit of an entropy index is that it provides a single score that measures both breadth and depth, with slightly more emphasis on depth. For example, the measure we used for information acquisition was

$$
\sum_{i=1}^{N} F_{i} \ln \left(1 / F_{i}\right)
$$

where $F_{i}$ is the frequency of acquisition from $i$ th party $\left(\mathrm{F}_{\mathrm{i}}\right.$ is computed as a percentage of the total frequency score). The two networking measures spanned: customers, suppliers, competitors, other businesses, sales/distribution agents, universities, other research institutions, government agencies, market research organizations, advertising agencies, consultants, parent companies, overseas business units, other business units, and fellow colleagues. The information and know-how sourcing measures included all of these sources plus libraries, published sources, and the internet. The innovation construct was based on fourteen items that covered: new and modified products and services, prototype developments, manufacturing and service techniques, administrative and managerial practices, policies and procedures, marketing techniques, patents applied for or received, publications in book, journals or technical outlets, formal presentations at conferences/seminars, and licensing rights sold or purchased. The absorptive capacity, decision making (comprehensiveness, creativity and consensus), new knowledge, and market/financial performance constructs were all created using reflective measures. The Cronbach Alphas for these measures ranged from 0.89 for organizational absorptive capacity to 0.71 for creativity in problem solving with between four (market/financial performance) and seven (absorptive capacity measures) items for each construct.

15. Ruggles, op. cit.

16. A.H. Gold, A. Malhotra, and A.H. Segars, "Knowledge Management: An Organizational Capabilities Perspective," Journal of Management Information Systems, 18/1 (Summer 2001): 185-214.

17. S. Pan and H. Scarbrough, "Knowledge Management in Practice: An Exploratory Case Study," Technology Analysis and Strategic Management, 11/3 (September 1999): 359-374.

18. R. McDermott, "Why Information Technology Inspired But Cannot Deliver Knowledge Management," California Management Review, 41/4 (Summer 1999): 103-117.

19. M.S. Granovetter, "Problems of Explanation in Economic Sociology," in N. Nohria and R.G. Eccles, eds., Networks and Organization: Structure, Form and Action (Boston, MA: Harvard Business School, 1992).

20. J. Nahapiet and S. Ghoshal, "Social Capital, Intellectual Capital, and the Organizational Advantage," Academy of Management Review, 23/2 (1998): 242-266.

21. S.S. Cohen and G. Fields, "Social Capital and Capital Gains in Silicon Valley," California Management Review, 41/2 (Winter 1999): 108-130.

22. G. Szulanski, "Exploring Internal Stickiness: Impediments to the Transfer of Best Practice Within the Firm," Strategic Management Journal, 17 (Winter 1996): 27-43.

23. C. O'Dell and C.J. Grayson, "If Only We Knew What We Know: Identification and Transfer of Internal Best Practices," California Management Review, 40/3 (Spring 1998): 154-174.

24. This number is an aggregation of six individual measures-the effectiveness of organizational incentives to: seek information, record information, distribute information, attend seminars, update skills, and update knowledge. 
25. The individual measure here is identical to that given in note 5 except that the question assesses the individual's actions. The measure in Table 2 is the difference between the two assessments-i.e., individual activity minus organizational incentives.

26. Pan and Scarbrough, op. cit.

27. T. Davenport and L. Prusak, Working Knowledge: How Organizations Manage What They Know (Cambridge, MA: Harvard University Press, 1998).

28. H. Itami and T.W. Roehl, Mobilizing Invisible Assets (Cambridge, MA: Harvard University Press, 1987).

29. Nonaka and Takeuchi, op. cit. 